\title{
Discussion: Expected behaviour and actual behaviour - is there a difference?
}

\author{
Phil Parker \\ Transport Planning Associates, Bristol, UK (phil.parker@tpa.uk.com) \\ (Orcid:0000-0002-6957-6636)
}

Andrew Fraser

Transport Planning Associates, Bristol, UK

\section{Contribution by Andrew Fraser}

Among other things, it is asserted in this paper that the most important factor affecting road safety is 'lower speed', and it is suggested that conformation with road-engineering standards may not result in sites that can be considered safe (Parker, 2019).

While the Design Manual for Roads and Bridges (DMRB) may have its imperfections, is not the application of appropriate standards precisely what satisfies the demand to travel safely at high speed? How safe would sites be without the application of standards? Is not the most important factor matching speed to circumstances, rather than 'lower speeds'?

Standards are required to assist those involved in design, but they may not necessarily be fully conversant with the research supporting them. They have evolved and should continue to do so. Perhaps Manual for Streets and Manual for Streets 2 (MfS2) are part of the evolutionary process.

It is true, however, that standards and design ought to take account of actual human behaviour (i.e. that which we should really expect) rather than some theoretical behaviour, as the 'Priority systems' section suggests.

This has a bearing on the content of the sub-section on junction visibility within the 'Standards' section, where reference is made to an 'extensive academic study', which concluded 'that there is no proven relationship between provision of visibility and improved safety'.

A summary of the study, contained in MfS2, seems to show that no account was taken of (e.g.)

- traffic volume

- parked vehicles

- actual approach speeds

- main road curvature

- side road location in relation to any main road curve present.
Furthermore, the sites selected were a mixture of T-junctions and crossroads! It is, perhaps, no wonder that a relationship could not be discovered.

In fact, there may be no simple relationship to be found anyway, since perception (an aspect influencing human behaviour) may be the main factor in accidents involving the untimely emergence of a vehicle from a minor road, and the failure of which may be quite independent of visibility.

Presumably, recommended visibilities give road users time to react to each other's presence but they cannot protect them entirely from failures of perception. Those who wish to reduce the $y$-distance should think very carefully before they do so. Certainly, one would expect very clear reasoning within the Exception Report appended to the 'Safety Audit'.

Regarding cycling on footways, the 'debate' about risk is hardly the point. Pedestrians are greatly discomfited by cyclists, who they expect to be provided for, by whatever means, within the carriageway. Despite the foregoing, however, one cannot but agree with the author's final paragraph.

\section{Authors' reply}

The author agrees that standards are required to assist designers but they are too frequently applied rigorously by rote and in isolation. Nevertheless, they are a useful starting point. However, it can be too convenient to measure something and compare it against what can often appear to be an almost randomly derived number or collection of numbers and draw a definitive conclusion. Engineers like to measure things and translate them into something that they can understand to make sense of the world - that is, numbers. That way of thinking confirms Kahneman's 'illusion of validity'. Achieving a standard does not necessarily make a site safe and similarly not achieving a standard may not make a site unsafe. Designers need to understand the first principles of the standards they are using, where they come from, what they mean and when they can be applied, and not hide behind routine and rigid application. 
The many variables used to challenge the MfS2 study also confirm the complexities involved and how the mere application of a single standard of a $y$-dimension value may lead to oversimplification. And what is the correct SSD for the $y$-value anyway? For $30 \mathrm{mph}$ take your pick from 90,70 or $50 \mathrm{~m}$ from DMRB, 43 or $40 \mathrm{~m}$ from MfS, $34 \mathrm{~m}$ from Brake the road safety charity or $23 \mathrm{~m}$ from the Highway Code. The author agrees with the comment that 'no simple relationship can be found' and this is what MfS chapter 10 also concludes! Nevertheless, this simple relationship is frequently rigorously applied without recognising and considering the individual characteristics of the site!

With respect to cycling provision the author would still strongly argue that shared cycleway/footways are safer than segregated cycleway/footways. Cycling in the road leads to approximately 100 cycling fatalities annually. Pedestrian/ cycling conflict casualties are miniscule. The greater risk to pedestrians is with 'safe' systems when crossing the road. Average annual pedestrian casualties taken from the office of national statistics data for Great Britain for 2015/2016 are frighteningly revealing. 'Killed' and 'Seriously Injured' figures for pedestrians crossing on these facilities are as follows

- 160 for zebra crossings (of which five fatal).

- 276 for pedestrian facilities on light-controlled junctions (of which 22 fatal).

- 335 for stand-alone light-controlled crossings (pelican, puffin, toucan and the like) (of which 26 fatal).

Regardless of perceived 'discomfort' the author would rather be uncomfortable and as a result very aware, than comfortable in hospital or worse. These actual risks from accepted national data are given too little attention. However, the reasons for these accidents on what the general public would regard as 'safe' systems are more worthy of attention than the perceived risks with cyclists that are unsupported by data. This returns to the whole theme of the paper concerning actual and expected behaviour!

Further to this issue encouraging safe active travel for all users has to be given greater priority. Too frequently cycling facilities within the carriageway are compromised and completely unattractive to less confident users who we are trying to encourage. The same applies to cycling facilities within footways and the concern for the discomfort of pedestrians. A well designed and significant rebalancing of street space to provide safe cycling and walking is urgently required to provide comfort to pedestrians and cyclists alike. In the CIHT Transportation Professional July/August 2019 article on active travel, Martin McDonnell advises the need for billions rather than tens of millions (to be spent) 'to really change things'. However, how authorities prioritise this can be revealed by the way they spend their budgets. As an example, the 5-year budget of $£ 175 \mathrm{~m}$ for Active Travel reported by Highways England to the 1/5/19 House of Commons select committee on Active Travel, sounds impressive but is approximately $1 \%$ of the overall budget of $£ 15$ billion (for the cycling element of $£ 100 \mathrm{~m}$, this is just $0 \cdot 7 \%$ ). Therefore, their priorities are very clear. And this balance has to be rectified.

\section{REFERENCE}

Parker P (2019) Expected behaviour and actual behaviour - is there a difference? Proceedings of the Institution of Civil Engineers Municipal Engineer 172(1): 18-25, https://doi.org/10.1680/jmuen. 16.00055 . 